\title{
Cross Ethnic Friendship among Multi-ethnic Students and Teacher's Role in Supporting Cultural Diversity in School
}

\author{
Yasmin Ahmad ${ }^{1, *}$, Mohd Kasturi Nor Abd Aziz ${ }^{1}$,Suzana Sulaiman ${ }^{1}$, Suhana Abdul Mutalib ${ }^{1}$ and Nurul Naimah \\ Rose $^{1}$
}

${ }^{1}$ School of Human Development and Technocomunication, Universiti Malaysia Perlis, Perlis, Malaysia

\begin{abstract}
This article presents an in-depth discussion about cross ethnic friendship among students and teacher's role in supporting the cultural diversity that exists in school. The school which consist of students from various ethnic groups provide space and opportunities for students to interact socially with peers either from the same or other ethnic groups. On the other hand, the school that consists of only one ethnic group limits the opportunity for students to interact with friends from different ethnic groups. Students who have attended the schools that are not diverse in terms of ethnicity were reported having more friends from the same ethnic group. A positive relationship between individuals from different ethnic groups led to the reduction in prejudice, enhance the sense of common identity and closeness among individuals. Teachers as agents of unity should play an important role in assisting students to acquire the necessary social skills that enables them to interact effectively with students from different ethnic, cultural and languages which consequently create a harmony cross ethnic friendships among multi-ethnic students in school.
\end{abstract}

\section{Introduction}

Malaysia is a country that consists of a multi-ethnic society, culture, way of life and history [1]. In every society, the education system is closely related to the needs of society due to the symbiotic relationship that exists between education and society. The education system cannot ignore the political, economic and cultural ideologies that shape their environment. In Malaysia, since independence, one of the objectives is national unity. Therefore, all educational policies have outlined the unity as the most important objective [2].

Razak Report in 1956 is the basis of the formation of national policies which related to education such as the Rahman Talib Report. The education system in Malaysia reflects the diversity of cultural and linguistic, especially at the primary level. Under the Education Act 1961 and the Education Act 1996, there are several streams using different medium of instruction across the primary, secondary and higher education level [3]. Students can learn their native language, while the same curriculum and syllabus were used to build national identity and the spirit of patriotism. In addition, Malay Language is compulsory in SJKC (National Chinese School) and SJKT (National Tamil School), while English is compulsory for all. At the secondary school level, most of the students from National Primary School, SJKC and SJKT will proceed to National Secondary School. But, there are also Chinese independent schools and Islamic religious schools that will attract small number of students [3. Multiple streams at the primary school level allow the evacuation of linguistic and cultural from Malaysia's three main communities, the fact is students from different ethnic groups tend to remain separate until the secondary schools and higher education level [3].

The government have implemented a variety of approaches to promote national unity and patriotism among the diverse ethnic groups in Malaysia [1]. However, the issue of racism that threatens the unity and harmony of the country still occurred [1]. Every ethnic group would protect their rights and privileges, thus creating the social boundaries. These boundaries can lead to ethnic tensions and conflicts between ethnic groups [2]. It is important to emphasize the value of ethnic diversity and national unity. Students from various ethnic backgrounds should know and appreciate the attitudes, institutions and traditions shared by all Malaysians [4].

\section{Interethnic Groups Relation}

The relations which have occurred among students from the same or diverse ethnic groups will influence the development of ethnic identity of an individual [5-6]. Theory of intergroup contact suggested that under a certain circumstances, an individual who have more

\footnotetext{
* Corresponding author: yasminahmad $@$,unimap.edu.my
} 
intergroup contact, exhibit a positive traits against friend from out group [7].

Study has shown that a positive relationship between individuals from different ethnic groups lead to a reduction of prejudice [8], increase the sense of common identity [9] and closeness between individuals [10]. Pettigrew and Tropp (2006) reported that a relationship between groups has a positive effect in the reduction of prejudice against a whole group of a friends and not just specific to a friend who has a relationship with an individual.

In one study that examined the relationship between intergroup contact and ethnic's identity, it was discovered that Koreans who lives in China and have more social interaction with Chinese society have a low levels of ethnic identity because discrimination often occurs [11].

Based on the context of relations between ethnic groups in Malaysia, ethnic relations are very complex, complicated and sensitive, especially when it comes to the issues of religion, culture and language which plays as an essential features in the competitions of identity based on a phenomenon that was formed by the British in the context of colonialism [12].

The dynamics relationship between group determine the changes in the construction of one's identity and way of life of an individuals who are living in a multicultural society and how they open and close with each other from social and cultural ethnic perspectives [13]. When individuals have an interaction, they cannot ignore in-group members, which is what is specific, distinctive and unique to the culture of their own ethnic group, but also a similar feature to outside groups [13].

\section{Cross Ethnic Friendship}

A closeness of cross ethnic friendship will reduce prejudice between ethnic groups [14-18]. According to Yusof (2006), cross ethnic friendships are more common in schools with students from various ethnic groups. Most of the research on cross ethnic friendship have explained about an effect of closeness in cross ethnic friendships [17]. Research conducted in four European countries have shown that the majority ethnic who build a cross ethnic friendships with minorities exhibit a reduction in bias against ethnic minorities [17].

Based on the study of the relationship between different ethnic groups, it consistently shows that the relations between ethnic groups can be positively managed to reduce prejudice against friends from different ethnic groups [7]. For example, respondents from ethnic majority in Germany, France, Netherlands and United Kingdom who have a good friends from minority ethnic groups were reported not only have lower prejudice against their friends but also diminish in prejudice against other minority ethnic groups as well [17]. Based on a study conducted on more than 1,000 senior students at the University of Michigan, it was found that seniors who have more contact with students from different ethnic groups, have more close friends from other ethnic groups and those who have more interaction with colleagues from other ethnic groups were reported to have more intellectual engagement, critical thinking and support the diversity exist among them [19].

Cross ethnic friendship is a complex process but certainly it would be benefit for the students in a positive way. Students could develop more positive attitudes toward intergroup interaction such as they would be more comfortable to mix around with friends of different ethnic background. It also develops a strong sense of empathy and caring for others [20]. This would create a harmonious and balance social interaction whereby everyone is included in the group. It will lead to low the level of conflict among students. In terms of psychological aspect, students would feel safe and less victimized by peers [21]. According to a study conducted by Hamm (2000), he found that by having a cross ethnic friendship, it also have been associated with having high scores on the importance and positive perception to any other ethnic group.

Research on friend selection among students in the secondary schools that contained of various ethnic students have shown that friendship among students were from the same ethnic group [22-23]. The diversity of peers based on ethnicity may be less important to the students whether in the minority or majority ethnic group from a residential area consisting of a multi-ethnic society [19]. A friendship pattern among students who have attend a school consisting of many students from the same ethnic group show a tendency to have a friend from the same ethnic group [22].

Theory on intergroup contact suggested that individuals should have the opportunity to interact with someone from other ethnic groups in everyday relationships [24]. Many studies have proved the importance of an opportunity to interact in the context of macro variables such as ethnic diversity [25].

The school consists of students from various ethnic group provide an opportunities for students to interact with friend from the same ethnic and also different ethnic background [24]. On the other hand, by attending schools consisting of student from the same ethnic group, students reported having more friends from the same ethnic group [22]. Schools that have a students which are less diverse in term of ethnicity, however only provide opportunities for students to interact with peers from same or different ethnic but not both in the same time [24].

\section{Multi-ethnic School Environment}

Multi-ethnic school environment in Malaysia is like in National School and National Secondary School. This type of school usually consist a students from various ethnic groups such as Malay, Chinese, Indian and other minority ethnic groups. The school consists of students from various ethnic groups provide an opportunity for students to build a friendships with peers from different ethnic background, unlike school attended by only one ethnic group where students do not interact with peers from different ethnic backgrounds [26]. Exposure to diversity in the classroom and cross ethnic friendship can 
lead to social benefits in the future [18]. Theory of intergroup contact suggested that individuals should have an opportunity to interact with their peers from other ethnic groups in their daily interactions. Many scholars have discussed the importance of an opportunity to have a relationship in the context of macro variables such as a diversity [25].

Schools which are less diverse in terms of ethnicity, however, only provide opportunities for students to interact with the same or different ethnicity but not both in the same time [24]. According to a study conducted by Yip, Seaton and Sellers (2010), although there are opportunities to interact with peers from the same ethnic or different ethnic background, students actually does not interact based on an opportunity of the diversity. One of the factors was the barriers from the institution, e.g. class arrangement that do not provide opportunities for students from different levels of academic achievement to interact [24,27].

Studies of Dutch adolescent without influenced by attending a school that consist of a students from diverse ethnic background whereby at least half of the student population is non-Dutch have discovered that $16 \%$ of them were reported having no contact with peers from non-Dutch [28]. Outside of the school, where students are expected to have more opportunities whether to get involved or not in the intergroup contact, it was reported that $45 \%$ of Dutch students have no inter-ethnic relation or only happened at minimum levels [28].

A study which examines the ethnic diversity in schools and a choice of friend among students in secondary schools have found that the higher proportion of students based on ethnicity, students will be more inclined to build a friendships with peers from the same ethnic group [22-23].

The study of Black and White students who attending the integration school have shown that most of the students were reported having a close friend from other ethnic groups [29].

\section{Cross Ethnic Friendships among Schools' Students in Malaysia}

Country such as Malaysia has a diversity of ethnics resulted from period of colonial history. Therefore, early exposure to cultural differences is vital in order to build a positive attitude towards other ethnic group. A positive attitude is a strong foundation to strengthen the relationship among multi ethnic society. The early exposure of cultural difference begins from school particularly in primary school. Students from various ethnic backgrounds such as Malays, Chinese, Indians and others would form cross ethnic friendships through interaction during the learning process. Most common factors to form a friendship are based on similarity and availability [21].

Despite the positive benefits of cross ethnic friendship, school students prefer to be in the same ethnic group [4]. Similarly, the friendship among students from multi-ethnic groups in Malaysia are still inclined with a friend from the same ethnic group. This situation exists because most of students e.g. Malays,
Chinese and Indians students at the primary school level have attended schools mostly based on their ethnicities. Ethnic segregation in educational context led the interaction between students from different ethnicities to be limited and rare [30-31]. The majority of students from various ethnic groups in secondary schools are mostly comfortable hanging out with friends from the same ethnic group [32]. Based on the study conducted by Vellymalay (2014), students from various ethnic groups in secondary schools tend to build a friendships with peers from the same ethnic group as compared to build a cross ethnic friendship. According to a study conducted by Ahmad (2011), even though students from a multiethnic school environment has a lot of opportunities for social interaction with friends from different ethnic group, however, the social interaction mostly occurred among same ethnic group. Students in a multi-ethnic school environment still have less social interaction with friends from different ethnic groups. Consequently, this led to the construction of the friendship based on the same ethnics group than building a cross ethnic friendships.

According Jamil et al., (2004), students from SJKC and SJKT are having difficulty to build relationships with students from different ethnic background when they were in secondary school. According to a study conducted by Ahmad (2011), Malay students who have attend schools that consist of majority students from Malay ethnic group are not willing to carry out activities together with students from other ethnic groups. This situation makes a cross-ethnic friendship among students are difficult to build especially when there were in secondary school.

\section{Teachers' Role in Supporting a Cultural Diversity in Schools}

The school environment and teachers play an important role where teachers themselves need to be aware of cultural diversity that exists in the classroom [1]. An anti-bias approaches in teaching and learning focusing on identity formation among students is to provide students with the ability to connect with the real world which contains diversified cultures, languages and ethnicity [1]. Chow (2007) stated that to teach multiethnic students effectively, teachers must be willing to bear a difficult responsibility and have a critical thinking. It is important to create an atmosphere where students feel safe to interact across the differences that exist between ethnic groups [18].

Teachers play an important role in promoting cross ethnic friendship among students [33]. Every student who comes to school brings together their culture, way of life and ethnic identity. It is influenced and shaped by the social background of students, culture, families, communities and beliefs or their religion [33-34]. Children should be educated and made them understand from the early stage about life in multicultural society. Understanding, respect, tolerance and the erosion of prejudice must be established among children to create a harmonious of social interaction [35]. 
According to Banks (2001), teachers and school administrators should carry out the following principles in establishing the relationship between ethnic groups existed among the students;

I. Schools must create or make a key feature of cross ethnic friendship among students as a step to improve relations between students from different ethnic groups.

II. Students should learn about stereotypes and other related bias would negatively affect ethnic relations.

III. Students should be taught about the values shared by almost all ethnic groups such as justice, equality, freedom, peace, humanity and virtue.

IV. Teachers should help students acquire the necessary social skills to interact effectively with students from different ethnic groups, culture and language.

V. Schools should provide opportunities for students from different ethnic group, cultural and language to interact socially in conditions designed to reduce fear and anxiety between ethnic groups.

In order to preserve democracy in terms of social changes and reducing ethnic polarization, teachers should set primary goals as the way to be an effective teacher who teaches students from different cultural and ethnic backgrounds [33]. One of these goals is that the teacher must help students to describe their ethnic identity and to be use it effectively with the members of their ethnic groups. Students must be clear with ethnic and their own identity before they can interact socially in a positive way with people from other ethnic groups. Teachers should also educate students about acceptance of their self and not promoting the racism. Although there are a students who are from a multi-ethnic society backgrounds, students must be taught to accept their own ethnic identity and become comfortable with it. Student must also learn how to use their ethnic identity effectively. They must also learn how to interact with their peers from other ethnic groups and how to practically solve conflicts [33].

Students from minority ethnic groups must work between the two ethnic social environments, which are in their ethnic and community groups and within the dominant ethnic group. In the context of Malaysia, teachers should help students from minority ethnic groups, which are Chinese and Indian students to learn how to interact in their own ethnic group and with the majority ethnic group. With the role of teachers in helping students to learn harmonies ethnic relations, it will help ethnic minority groups to act in good possible way in other culture and ethnic groups [33].

Teachers can also play a role in either to reinforce or reject multiculturalism [36]. Teachers who are sensitive to culture always understand and deal directly with the sensitivities that exist between cultures [37-38]. As agents who are sensitive to culture, education among teachers should promote the construction of knowledge, skill and a required sensitivity [39]. Dukes and Ming (2006), emphasized the importance of teachers' role as an agents of cultural diversity. The teachers' role is very important because they serve as a model for students to achieve goals in understanding the cultural diversity that exist among them [1]. Aspects of teaching that is not in accordance with the diversity of students' cultural backgrounds will lead to a cultural clashed [40-42]. Grootboom (2007), state that student in a class consisting of diverse cultures tend to have a lot of problems based on the culture mixing.

Teachers should help students recognize that not only an ethnic groups have a differences and diverse, but individuals from the same ethnic group are also different from each other [43-44]. At the same time, students should also be encouraged to identify common features between peers from different ethnic groups. Learning about ethnic cultural diversity should involve all students without forming any gap or separation between the ethnic minority and majority students as an effort to encourage students to interact with each other [44-45].

\section{Conclusion}

A multi-ethnic school environment provides an opportunity for the students from various ethnic group to interact socially with peers from other ethnic groups and build a cross ethnic friendships. However, based on a review, it shows that there are multiple findings in terms of building a cross ethnic friendship even though the students were in the multi-ethnic school environment. Students from various ethnicities reportedly still carry out activities either in classroom or outside the classroom and build a friendship based on their respective ethnic groups. Therefore, teachers should play an important role in promoting ethnic relations among students with a range of programs either in classroom or outside the classroom to ensure the students interact socially with peers from other ethnic groups. Teachers should also be trained with multicultural teaching methods as a basis to teach students from different ethnic groups and cultures.

\section{References}

1. R.M. Majzub, S. Hashim, E. H. Johannes, Procedia - Social and Behavioral Sciences, 15, 1573-1579 (2011)

2. R. Mustapha, N. Azman, F. Karim, A. R. Ahmad, M. A. Lubis, Social Integration among Multiethnic Students at Selected Malaysian Universities in Penisular Malaysia: A Survey of Campus Social Climate. AJTLHE, 1(1), 35-44 (2009)

3. Government Transformation Programme: The Roadmap. (2010). Prime Minister's Department, Malaysia.

4. A. R Hamdan, M. N. Ghafar, A. A. Ghani, Fostering inter group contacts among multiracial students in Utm. Paper presented at International Conference on Learner Diversity: ICELD 2010. Bangi:UKM.

5. R. Alba, V. Nee, Remaking the American mainstream: Assimilation and contemporary immigration (Cambridge, MA: Harvard University Press, 2003) 
6. A. Portes, R. G. Rumbaut, Legacies: The Story of the Immigrant Second Generation. New York: Russell Sage Foundation.

7. T. F. Pettigrew, Intergroup contact theory. Annual Review Psychology 49, 65-85 (1998)

8. L. E. Molina, M. A. Wittig, Journal of Social Issues 62 (3), 489-509 (2006)

9. J. A. Nier, S. L. Gaertner, J. F. Dovidio, B. S. Banker, M. W. Christine, C. R. Mary, Changing interracial evaluations and behavior: The effects of a common group identity." Group Processes \& Intergroup Relations 4(4), 299-316 (2001)

10. L. Tropp, Social Psychology Quarterly 70(1), 7081(2007)

11. L. Lee, H. Carollee, C. Brandt, Merrill-Palmer Quarterly (53) 3, Article 3 (2007)

12. S. A. Baharuddin, Many ethnicities, many cultures, one nation: The Malaysian experience. Institut Kajian Etnik (Universiti Kebangsaan Malaysia, 2008)

13. M. Filpisan, Tomuletiu Adriana-Elena, A. Moraru, M. Stoica, B. Gorea, A. Solovastru, Procedia Social and Behavioral Sciences 15, 3263-3267 (2011)

14. A. Eller, D. Abrams, D. (2003). "Gringos" in Mexico: Cross-sectional and longitudinal effects of language school-promoted contact on intergroup bias. Group Processes \& Intergroup Relations, 6, 55-75(2003)

15. S. Levin, L. Van Lar, W. Foote, Journal of Applied Social Psychology 36(6), 1471-1501 (2006)

16. S. Paolini, M. Hewstone, A. Voci, J. Harwood, E. Cairns, (2006). Intergroup contact and the promotion of intergroup harmony: The influence of intergroup emotions. In R. Brown \& D. Capozza (Eds.), Social identities: Motivational, emotional and cultural influences (pp. 209-238). Hove, England: Psychology Press.

17. T. F. Pettigrew, Generalized Intergroup Contact Effects on Prejudice. Personality and Social Psychology Bulletin 23(2), 173-185 (1997),doi: 10.1177/0146167297232006.

18. T. B. Smith, L. Sylva, Journal of Counseling Psychology 58, 42-60 (2011)

19. P. Gurin, E. L. Dey, S. Hurtado, G. GurinDiversity and higher education: Theory and impact on educational outcomes. Havard Educational Review 72 (3), 330-366 (2002)

20. X. Chen, S. Graham, Cross-ethnic friendship and intergroup attitudes among Asian American adolescents. Child Development, 749-764 (2015)

21. S. Graham, A. Muniksma, A. Juvonen, Child Development 469-483 (2014)

22. G. Kao, K. Joyner, Social Science Quarterly 87, 972-992(2006).

23. E. Vaquera, G. Kao, Sociological Quarterly, 47: 375-396(2006)

24. T. Yip, E. Seaton, R. Sellers, Interracial and Intraracial Contact, School-Level Diversity, and Change in Racial Identity Status Among African American Adolescents. Child Development, 81(5), 1431-1444 (2006)
25. X. De Souza Briggs, City \& Community, 6: 263290 (2007). doi:10.1111/j.1540-6040.2007.00228.x

26. H. McGlothlin, M. Killen, C. Edmonds, British Journal of Developmental Psychology, 23, 227250 (2005). doi:10.1348/026151005x26101.

27. W. N. Kubitschek, M. T. Hallinan, Social Psychology Quarterly 61(1):1-15 (1998)

28. C. N. Masson, CM. Verkuyten, Journal of Applied Social Psychology 23, 156-168 (1993)

29. D. L. DuBois, B. J. Hirsch, School and neighbourhood friendship patterns of blacks and whites in early adolescence. Child Development 61, 524-536 (1990)

30. S. Osman, Ikatan etnik dan kelas di Malaysia (Bangi, Universiti Kebangsaan Malaysia, 1989)

31. N. M. Yusoff, (2006). Pola interaksi sosial dalam kalangan murid multietnik di sekolah kebangsaan. Tesis PhD. USM.

32. S. K. Vellymalay, Journal of Human Capital Development 7(2), 47-61

33. J. A. Banks, Race, culture, and education: The selected works of James A. Banks (Oxon: Routledge, 2006)

34. J. A. Banks, (1989). Multicultural education: Characteristics and goal. In J. A. Banks \& C. Banks (Eds.), Multicultural education: Issues and perspective. Boston: Allyn and Bacon.

35. H. Jamil, Pendidikan berbilang budaya: Meningkatkan kefahaman pelajar tentang kepelbagaian budaya masyarakat melalui pendidikan sejarah. Diges Pendidik 2, 30-40 (2002)

36. J. A. Spinthourakis, E. Karatzia-Stavlioti, Y. Roussakis, Pre-service teacher intercultural sensitivity assessment as a basis for addressing multiculturalism. Intercultural Education, 20(3), 267-276 (2009)

37. G. M. Chen, W. J. Starosta, Foundations of intercultural communication. (Boston, MA: Allyn \& Bacon, 1998)

38. A. E. Fantini, A. E. (2000), A central concern: Developing intercultural competence'. In SIT Occasional Paper Series. Brattleboro (VT), 25-42 (2000)

39. A. H. Hains, E. W. Lynch, P. J. Winton, Moving towards cross-cultural competence in lifelong personnel development: A review of the literature: Early Childhood Research Institute on Culturally and Linguistically Appropriate Services University of Illinois at Urbana-Champaign. Retrieved from; http://clas.uiuc.edu/techreport/tech3.html.

40. J. Necochea, Thrust for Educational Leadership 27, 20-23 (1997)

41. C. Casteel, The Journal of Educational Research 92, 115-120 (1998)

42. G. Cartledge, C. Kea, D. Ida, Teaching Exceptional Children 32, 30-37 (2000)

43. A. D. Pellegrini, Nature, 467, 27 (2010)

44. L. Pellegrini, European Journal of Teacher Education, 33(2), 113-125 (2010)

45. L. Derman-Sparks, P. G. Ramsey, What if all the kids are white? (New York: Teachers College Press, 2006) 